\title{
Tratamiento informativo sobre periodismo ecológico en la página web de Diario El Comercio
}

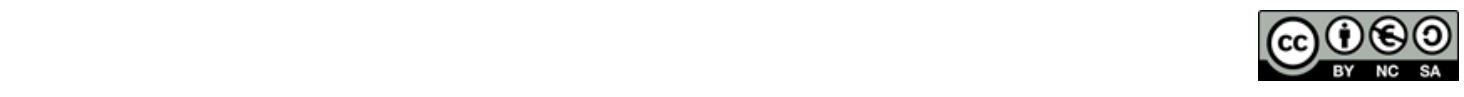

Informative treatment of ecological journalism on the website of Diario El Comercio

Raúl Guillermo Zambrano Pontón. ${ }^{1}$, Daniela Carolina Ruiz Sánchez. ${ }^{2}$, Myriam Elizabeth Murillo Naranjo. ${ }^{3} \&$ Fermín Andrés Haro Velasteguí. ${ }^{4}$

\begin{abstract}
.
DOI: https://doi.org/10.33262/concienciadigital.v4i3.1.1813

Introduction: This article reflects on the approaches that the newspaper El Comercio, Ecuador carries out on ecological journalism, on its website, between the months of May and October 2019. Objective: Analyze the information treatment on ecological journalism on the website of Diario El Commerce. Methodology: The design used was of a mixed type: qualitative-quantitative, the thesis of Ruiz, D was taken as a reference. Content analysis was used as a technique, 42 publications were defined as a sample during the six months analyzed, and interviews were conducted. structured to experts on the subject. Results: It was found the amount that was written on the subject studied, what was disseminated and the way in which it was carried out. To obtain data, three matrices were used that allowed the analysis and counting of the publications made and two matrices with which the opinion of the interviewees was classified, allowing to discover in quantities how much is written about ecological journalism and in quality what is

1 Universidad Nacional de Chimborazo, Carrera de Comunicación Social. Riobamba, Ecuador. gzambrano@unach.edu.ec. https://orcid.org/0000-0002-3497-4722

2 Universidad Nacional de Chimborazo, Carrera de Comunicación Social. Riobamba, Ecuador. dcruiz.fpcs@unach.edu.ec.https://orcid.org/0000-0002-5085-1140

3 Universidad Nacional de Chimborazo, Carrera de Comunicación Social. Riobamba, Ecuador. myriammurillo@unach.edu.ec. https://orcid.org/0000-0002-5141-353X

${ }^{4}$ Escuela Superior Politécnica de Chimborazo, sede Morona Santiago. Carrera de Contabilidad y Auditoría. Macas, Ecuador. fharo_velastegui@ hotmail.com. https://orcid.org/0000-0002-9421-4549
\end{abstract}


written, determining important aspects about the informative treatment and the relevance that is given to the ecological issue in Ecuadorian journalism. The most used genre was that of the informative note, with a total of 37 publications, 2 interviews and a report were also counted. Conclusion: During the study it was observed that the interactions and visualizations registered on this web page depended directly on the number of publications that the medium made, most of the analyzed news have a global focus and not a local one, which could cause the public not to you are fully identified with this information, feeling that what is reported does not affect you completely.

Keywords: ecological journalism, informative treatment, content analysis, digital journalism and web narrative.

\section{Resumen.}

Introducción: El presente artículo reflexiona los abordajes que diario El Comercio, Ecuador realiza sobre periodismo ecológico, en su página web, entre los meses de mayo a octubre de 2019. Objetivo: Analizar el tratamiento informativo sobre periodismo ecológico en la página web de Diario El Comercio. Metodología: El diseño utilizado fue de tipo mixta: cualitativa-cuantitativa, se tomó como referencia la tesis de Ruiz, D. Se utilizó como técnica el análisis de contenido, se definió como muestra 42 publicaciones durante los seis meses analizados, y se realizó entrevistas estructuradas a expertos en la temática. Resultados: Se encontró la cantidad que se escribió sobre el tema estudiado, qué es lo que se difundió y la forma en la que se realizó. Para la obtención de datos se utilizó tres matrices que permitieron analizar y contabilizar las publicaciones realizadas y dos matrices con las que se clasificó la opinión de los entrevistados, permitiendo descubrir en cantidades cuánto se escribe sobre periodismo ecológico y en calidad que es lo que se escribe, determinando aspectos importantes sobre el tratamiento informativo y la relevancia que se le da al tema ecológico en el periodismo ecuatoriano. El género más utilizado fue el de la nota informativa, con un total de 37 publicaciones, se contabilizaron también 2 entrevistas y un reportaje. Conclusión: Durante el estudio se pudo observar que las interacciones y visualizaciones registradas en esta página web, dependían directamente del número de publicaciones que el medio realizaba, la mayoría de noticias analizadas tienen un enfoque global y no local lo que podría provocar que el público no se encuentre totalmente identificado con esta información, al sentir que lo que se informa no le afecta por completo.

Palabras claves: periodismo ecológico, tratamiento informativo, análisis de contenido, periodismo digital y narrativa web.

\section{Introducción.}

El presente artículo reflexiona el tratamiento informativo del periodismo ecológico en la página web de Diario El Comercio, como pregunta de investigación se estableció ¿Cómo 
se trata el tema ecológico en la página web de Diario El Comercio?, con el objetivo de determinar los resultados descriptivos de la relevancia que se da a los temas ambientales en la página web de este diario, tomando en cuenta que la manera en la que los ciudadanos interactúan con los hechos noticiosos que acontecen en su entorno, se ha transformado gracias a las nuevas tecnologías, en espacios que han sido aprovechados por los medios de comunicación, quienes han adaptado su contenido a estas plataformas digitales con el objetivo de llegar a un público especifico de manera diferente.

Permitiéndonos identificar si se está dando la notabilidad que estos temas merecen por parte de los medios de comunicación en el ámbito nacional, teniendo presente que el pensamiento ecológico de una comunidad se determina por la forma en la que esta retoma la visión de su futuro, dejando atrás una visión antropocéntrica, que le permite universalizar un concepto de fraternidad entre las especies.

Se empleó metodología de tipo mixta: cualitativa y cuantitativa, como técnicas se usaron el análisis de contenido de 42 publicaciones realizadas en la página web del medio de comunicación mencionado, y la entrevista estructurada, que fue realizada a tres expertos en la rama del periodismo ambiental, el periodismo digital, la docencia en periodismo especializado y educación ambiental. Con esta aproximación se busca explicar la forma en la que se da tratamiento al periodismo de tema ecológico, la forma en la que se utiliza la narrativa web, cuanto se escribe y con qué relevancia informativa se lo hace. Esta investigación sirvió para comprender la forma en la que se presenta la información de tipo ecológico en los medios de comunicación, viendo esto como un accionar de responsabilidad que deben cumplir estos, como actores decisivos en el cambio de accionar de la sociedad.

El aporte teórico se encuentra en el importante aporte de autores como: Colombini (2008); Noci Díaz (2008); Fernández (2000); Grinberg (2008); García (2003); Larena (2005); Ramos (2017); Vega (2017); Scolari (2017); Salaverría (2004); Lezamiz (1997); Valenzuela (2020).

\section{Periodismo Digital}

Durante el siglo XXI con el nacimiento del internet los medios de comunicación fundados en la tradicionalidad del papel, la radio y la televisión, debieron consolidar sus espacios digitales, manejando las nuevas dinámicas que la web puso en juego.

En los años 90 cuando empezó a aparecer los primeros medios digitales en el mundo, Maturana, en Sánchez (2018, p. 3), determina que fue en 1991 que Internet empezó a tomar un aspecto actual, nació la primera página web y los medios de comunicación comenzaron a explorar las narrativas propias de este espacio digital, sin embargo, no fue hasta 1995 que varios periódicos de países de Latinoamérica lanzaron sus ediciones digitales.

El ciberespacio es entonces "un estado de percepción determinado, donde el lector, o usuario, ha desarrollado ya un nuevo modelo de interacción con la información y donde 
se enfrenta a códigos y lenguajes nuevos", Royo, mencionado en Díaz (2008, p. 56). Internet es más "que un nuevo modo de distribuir información, se trata de un medio completamente nuevo, con unas peculiaridades específicas que repercuten en la forma que se configura la información distribuida a través de ella", Pérez y Perea en Fernández (2000, p. 3).

Para muchos expertos uno de los principales beneficios que presenta el uso de plataformas digitales a la hora de difundir información es que esta puede reemplazarse en función de los intereses de su editor, López referenciado en Marcet, Murillo y Vizuete (2007, p. 320), conceptualiza a esta característica como "la ruptura de la periodicidad, hecho que se entiende como la posibilidad de que los contenidos pueden ir actualizándose de forma instantánea y constante".

Los nuevos medios están orientados hacia la acción, no hacia la contemplación; hacia el presente, no hacia la tradición. Ello no significa que carezcan de historia o que contribuyan a la desaparición de la conciencia histórica. Por el contrario, y en este caso, permiten que por primera vez el material informativo quede fijado de tal forma que en cualquier momento puede ser reproducido, Hans Magnus Enzensberger, referenciado en Zalcberg (2001, p. 169)

De tal forma el periodismo digital es el resultado de la disolución de las fronteras que dividían a los medios en función de su formato y soporte, constituyendo así mejoradas realidades mediáticas, que a comparación de sus versiones tradicionales han permitido que exista una comunicación eficaz e instantánea, basada en la retroalimentación entre emisores y receptores. Concibiéndose como:

"Un periodismo que utiliza un nuevo medio de comunicación, que es interactivo y permite una comunicación multimedia, que tiene diseño propio, que puede vincular con rapidez una información con sus contextos, antecedentes, etc., que tiene una potencialidad amplísima de servicio al lector, y que para su eficacia precisa de unos textos que utilicen una estructura interna y externa peculiar y un lenguaje funcional", Armentia en García (2003, p. 178).

\section{Narrativa Transmedia}

La expansión del Internet ha volcado al periodismo digital a envolverse en un constante crecimiento en torno al manejo de su contenido, se ha dejado de lado la idea de que escribir en la web significaba volcar lo que se emitía en los medios como la prensa, radio o televisión. Con la llegada de las múltiples innovaciones de la web, se presentan también nuevas formas en las que la información es presentada y difundida por la prensa que reside en el ciberespacio, el internet pone a disposición al periodista una cantidad inigualable de recursos hipertextuales, que deben ser aprovechados con el objetivo de enriquecer la narrativa web.

Este concepto fue introducido por Henry Jenkins en un artículo publicado en Technology Review en 2003, para autores como Scolari la narrativa transmedia presenta dos 
características esenciales que son expansión narrativa y cultura participativa, y la sintetiza en una fórmula:

Esquema 1: Formula de la narrativa transmedia

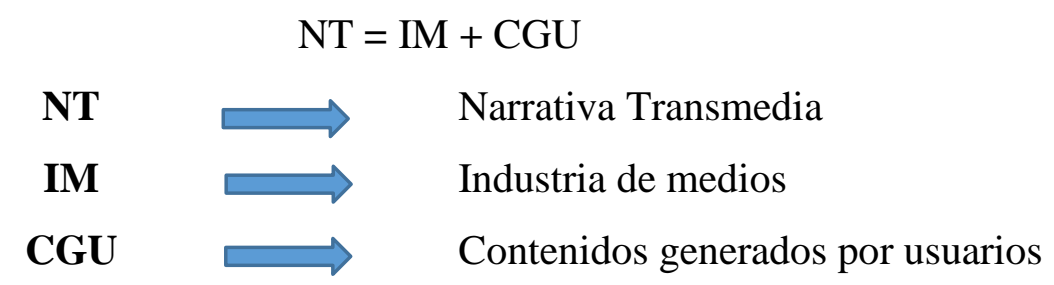

Fuente: Scolari (2017) / Elaboración propia.

Entonces una narración transmedia puede contar con dos características importantes:

La primera es que es una historia contada de distintas maneras en diferentes plataformas, es decir que el relato puede comenzar en un medio y continuar en otros, aprovechando lo mejor de cada uno para contarse y expandirse, Agustina del Molino, referenciada en Vega (2017, p. 85).

Prádanos $(2013$, sp.), contextualiza a la narrativa transmedia como "la técnica de contar historias a través de múltiples plataformas y soportes", dando importancia al aporte que representa la vinculación de cada elemento de estas plataformas. De tal forma la narrativa transmedia puede identificarse como un proceso, "donde los agentes implicados participan de manera activa y colaboran de algún modo en la configuración de un relato que posee un carácter expansivo", Abellán y Zamora (2016, p. 2).

\section{Géneros Ciberperiodisticos}

Los géneros periodísticos nacen de la necesidad de satisfacer la función básica del periodismo, la de transmitir de forma entendible hechos reales. A partir de las últimas décadas y con el aparecimiento de nuevas y mejoradas plataformas digitales, los medios tradicionales se han visto en la necesidad de acoplarse a estos nuevos entornos, generando una convergencia de medios y una hibridación de los géneros periodísticos clásicos, presentándose como "una característica inherente a la evolución de la prensa, que se acentúa en el caso de los medios digitales, gracias a la hipertextualidad, la multimedialidad y la interactividad”, Zúñiga y Valido (2017, p. 125).

Por su parte Salaverría, en Escandón (2019, p. 5) señala que:

La configuración de un nuevo lenguaje para los cibermedios incorpora tres novedosos ingredientes para el periodismo: multimedialidad la cual consiste en saber contar la historia combinando textos, imágenes y sonidos a la vez, la hipertextualidad que son enlaces que facilita la red para organizar las estructuras discursivas, mediante unidades de contenidos multifacéticos, y la interactividad que consiste en la interacción del autor y el usuario, capacidad de elección y respuesta, con los lectores activos. 
Para Ramos (2017, p. 70), estos géneros pueden entenderse como "nuevas formas discursivas que utilizan el ciberperiodismo para informar, analizar, interpretar y opinar acerca de los acontecimientos que conforman la realidad", para este autor los géneros ciberperiodisticos se basan en cuatro parámetros esenciales que son la multimedialidad, la hipertextualidad, la instantaneidad y la interactividad y los clasifica de la siguiente manera:

Tabla 1: Géneros Ciberperiodisticos

\begin{tabular}{|c|c|c|}
\hline PARÁMETROS & \multicolumn{2}{|c|}{ GENEROS CIBERPERIODÍSTICOS } \\
\hline MULTIMEDIALIDAD & Fotogalería & $\begin{array}{l}\text { Álbum digital y animado de fotografías } \\
\text { (ordenado secuencialmente) que muestra un } \\
\text { suceso noticioso. Cuenta con apoyo de un } \\
\text { título y regularmente pies de foto. }\end{array}$ \\
\hline \multirow[t]{2}{*}{ HIPERTEXTUALIDAD } & Archivo de audio & $\begin{array}{l}\text { Archivo digitalizado, que si es activado, } \\
\text { reproduce el audio de las declaraciones de } \\
\text { un personaje-noticia o de una producción } \\
\text { radial regularmente de carácter periodístico. }\end{array}$ \\
\hline & Archivo de video & $\begin{array}{l}\text { Archivo digitalizado, que si es activado, } \\
\text { reproduce el audio y las imágenes en } \\
\text { movimiento de personajes, lugares o hechos } \\
\text { noticiosos. }\end{array}$ \\
\hline \multirow[t]{2}{*}{ INSTANTANEIDAD } & Blog periodístico & $\begin{array}{l}\text { Medio de autoría centralizada, con } \\
\text { estructura cronológica, producido y } \\
\text { administrado por un periodista, quien escribe } \\
\text { sobre temas especializados y en el que los } \\
\text { usuarios pueden interactuar. Tiende a formar }\end{array}$ \\
\hline & Entre vista digital & $\begin{array}{l}\text { Conversación mediada por la tecnología } \\
\text { entre uno o varios entrevistados y los } \\
\text { usuarios de un medio, moderada } \\
\text { regularmente por algún periodista. }\end{array}$ \\
\hline \multirow[t]{3}{*}{ INTERACTIVIDAD } & Infografía & $\begin{array}{l}\text { Paquete informativo que comunica, mediante } \\
\text { la asociación texto-imagen y de manera } \\
\text { secuencial e interactiva, cómo ha ocurrido un } \\
\text { acontecimiento noticioso, con el objetivo de } \\
\text { facilitar al usuario la comprensión del hecho } \\
\text { o algunos de sus aspectos más significativos. }\end{array}$ \\
\hline & Especiales & $\begin{array}{l}\text { Espacio hipermedia (incorpora textos, } \\
\text { imágenes, audios y videos articulados } \\
\text { mediante el hipertexto), interactivo y } \\
\text { monotemático. }\end{array}$ \\
\hline & Podcast & $\begin{array}{l}\text { Producción en audio o video de carácter } \\
\text { periodístico que se entrega mediante un } \\
\text { canal de suscripción en forma automática y } \\
\text { regular en la computadora o en algún }\end{array}$ \\
\hline
\end{tabular}

Fuente: Alejandro Ramos Esquivel / Tomado de la tesis de Ruiz, D. 


\section{Periodismo Ecológico}

El periodismo nace como una de las herramientas más propicias para entrelazar ejes disciplinarios, culturales e ideológicos, ofreciendo a los públicos la posibilidad de adquisición de conocimientos esenciales, con los que pueden ser partícipes de cambios hacia un desarrollo social.

A lo largo de la historia la prensa minoritaria transcurrió lentamente hacia la de masas, dando espacio en este intervalo a que los relatos periodísticos de hechos noticiosos se conviertan en las principales atracciones en una lucha entre los diarios de la época por acaparar audiencias. El periodismo es, "en esencia, un ejercicio objetivista y apegado a los hechos sociales, la profesión debe adoptar una posición crítica y comprometerse con la solución de los restos de la ciudadanía," (Barranquero, 2019, p.66).

Por su parte en el periodismo ecológico tratado ya sea desde escenarios comunicacionales, gubernamentales o educativos es comparativamente nuevo, visto desde una perspectiva más transversal, tiene como objetivo ser un actor movilizador y promotor de transformaciones en la sociedad.

El trabajo informativo de los medios de comunicación en la formación de opinión parece incidir cada vez más en la adquisición de una cultura ambiental, permitiendo que el ciudadano conozca sobre sus obligaciones socio-ambientales y que actué en consecuencia de ese conocimiento.

No es hasta la década de los 60 , que el periodismo ambiental se vislumbra como una emergencia social, esto tras las múltiples denuncias de los medios que alertaban las consecuencias medioambientales de la posguerra, sin embargo, no fue sino hasta los años 70 que surgen los primeros artículos medioambientales. Ya con estos antecedentes, fue entonces que entre el 3 y 14 de junio de 1992 en Rio de Janeiro, se presencia uno de los acontecimientos más importantes, que marcaría el desarrollo del periodismo ambiental, la Conferencia de Naciones Unidas sobre el Medio Ambiente y el Desarrollo, o Cumbre de la Tierra, Colombini?, en Valenzuela (2020, p. 9).

La información ambiental permite comprender los elementos naturales y artificiales y explica cómo afectan la calidad de vida de la población, también incluye componentes administrativos, políticos, culturales y económicos y su aparición en los medios de comunicación social reclama rigurosidad en su tratamiento a través de funciones clave como su difusión y divulgación.

Algunos expertos han establecido como periodismo ecológico a aquel "que se ocupa de la información de actualidad que contextualiza, analiza los procesos y enumera los efectos de todo aquello que intervenga destructivamente en los ámbitos vitales”, Lezamiz (1997, sp.). Así mismo el periodismo ecológico presenta cinco características fundamentales: a) es un periodismo de investigación; b) es una forma del periodismo científico; c) es un periodismo educativo y pedagógico; d) es consciente de cumplir una responsabilidad 
social específica y e) debe ejercerse con profesionalismo, objetividad y responsabilidad, Bacchetta, en Grinberg (2018, p. 33).

Para Arturo Larena, "la honestidad y el rigor no están reñido con el entretenimiento y aunque no se trata de hacer un espectáculo del medio ambiente, se debe entender que es posible pasar de una audiencia minoritaria al gran público”, Larena (2005, p. 57).

De tal forma el periodista ambiental no necesita convertirse en un científico, pero deberá desarrollar todas las habilidades necesarias para ser un interlocutor idóneo, capaz de comprender la línea de pensamiento del científico, interpretar la incidencia de ese conocimiento en el marco el desarrollo global, y transmitirlo de modo que sea atractivo, primero para el editor del medio, y fundamentalmente, para el receptor, Colombini (2008, p. 60).

\section{Tratamiento Informativo}

El tratamiento informativo se puede delimitar como "el procesamiento de elementos como cifras, hechos, fuentes de información, datos y géneros periodísticos, que al ser difundidos constituyen un mensaje que cambia el estado de conocimiento del sujeto o sistema que recibe dicho mensaje" Merlos, Ramírez y Serrano (2012, p. 53).

Echeverría, en Gonzales (2018, p. 14), define "el tratamiento informativo como el modo en el que los medios impresos eligen la información; la transforman en imágenes y en textos, la ubican en las páginas y lo ponen en circulación”.

\section{Análisis de Contenido}

El análisis de contenido es una técnica que no solo permite analizar el estilo de un texto, sino que nos permite desarmarlo al punto de entender las ideas expresadas en este. Se basa así en la "lectura textual o visual, como instrumento de recogida de información, lectura que debe realizarse siguiendo el método científico, es decir, debe ser, sistemática, objetiva, replicable, y valida", Abela (2002, p. 2).

Bardin en Pulido (2015, p. 1147), contextualiza al análisis de contenido como "un conjunto de instrumentos metodológicos extremadamente diversificado, que se aplica al contenido de discursos, orientado al análisis de comunicaciones". Para Berelson, referenciado en López (2002, p. 173), el análisis de contenido es una "técnica de investigación que pretende ser objetiva, sistemática y cuantitativa en el estudio del contenido manifiesto de la comunicación"

Se presenta también como un conjunto de procedimientos interpretativos de productos comunicativos (mensajes, textos o discursos) que proceden de procesos singulares de comunicación previamente registrados, y que, basados en técnicas de medida, a veces cuantitativas (estadísticas basadas en el recuento de unidades), a veces cualitativas (lógicas basadas en la combinación de categorías) tienen por objeto elaborar y procesar datos relevantes sobre las condiciones mismas en que se han producido aquellos textos, o sobre las condiciones que puedan darse para su empleo posterior, Raigada (2002, p. 2). 


\section{El Comercio}

El Comercio, es un diario matutino del Ecuador, fue fundado en Quito el 1 de enero de 1906 en por los hermanos Cesar y Carlos Mantilla Jácome, en la actualidad se lo reconoce como uno de los más importante e influyentes a nivel nacional, (Coronel et al., 2013).

Desde su fundación este diario ha recibido un sin número de reconocimientos internacionales a motivo de su diseño e impresión, en enero del 2016 Grupo El Comercio, incursiona en el mundo de la televisión fundando Televicentro, convirtiéndose en un canal de cobertura nacional, en el mismo año se crea su sitio digital donde se publica información de relevancia nacional e internacional, constituyéndose en la actualidad como el medio con más interacción con la comunidad.

\section{Metodologia.}

La presente investigación es mixta cuantitativa-cualitativa, se realizó el análisis de contenido para lo cual se empleó una matriz que cuenta con siete columnas, distribuidas respetivamente en: día, tema, género periodístico, elementos de ayuda grafica o audiovisual, valoraciones, visualizaciones, teniendo en la última casilla una pregunta, para conocer si la noticia fue o no útil para los usuarios. Se utilizó también una entrevista estructurada, con un cuestionario diferente para cada entrevistado, con 13 preguntas enmarcadas en un mismo enfoque, los especialistas escogidos tienen experiencia en la rama del periodismo ambiental, el periodismo digital, la docencia en periodismo especializado y educación ambiental, la muestra observada corresponde a 42 publicaciones realizadas durante los seis meses analizados.

Como técnicas se utilizaron:

a. Análisis de contenido que nos permite obtener una descripción objetiva de un contenido comunicacional.

El análisis de contenido es un conjunto de procedimientos interpretativos de mensajes, textos o discursos, basado en técnicas de medida cuantitativas o cualitativas, que tienen como objetivo elaborar y procesar datos relevantes sobre las condiciones de producción o empleo posterior de dichos mensajes, textos o discursos”, Piñuel en Gonzáles (2015, p. 322).

b. Entrevista estructurada, se empleó este tipo de entrevista con la finalidad de entablar un dialogo con varios profesionales, tomando en cuenta que es una técnica en la que: un entrevistador solicita información a un entrevistado sobre un problema determinado, presupone entonces la existencia al menos de dos personas y la posibilidad de interacción verbal, Guerrero (2016, p. 7). 


\section{Resultados.}

En este epígrafe se muestra los resultados encontrados durante el análisis de las publicaciones realizadas en la página web de Diario El Comercio, en el periodo de mayo - octubre de 2019.

Para la obtención de datos en esta investigación se utilizó tres matrices que nos permitieron analizar y contabilizar las publicaciones realizadas y dos matrices con las que se clasificó la opinión de los entrevistados.

\section{Matrices para el análisis de contenido}

\section{a) Herramienta de diagnóstico}

Se utilizó como herramienta de diagnóstico, una matriz en la que se colocó datos como la fecha, el titular y el link de la publicación.

Con dicha matriz se creó una base de datos que nos permitió conocer cuántas noticias se subieron en la página web de Diario El Comercio, en el periodo de mayo-octubre de 2019, obteniendo como resultado que fueron 42 publicaciones.

\section{b) Matriz de análisis de contenido}

En esta matriz se colocó siete columnas, distribuidas respetivamente en: día, titular, género periodístico, elementos de ayuda grafica o audiovisual, valoraciones, visualizaciones, teniendo en la última casilla una pregunta, para conocer si la noticia fue o no útil para los usuarios.

Esta matriz nos dio datos cuantitativos de cada una de las publicaciones realizadas, es decir cuántas visualizaciones, interacciones, elementos de ayuda grafica o audiovisual registraban, en este proceso se encontró también que existían dos entrevistas y tres videos que constaban dentro de las 42 publicaciones estudiadas.

\section{c) Matriz de cronología}

Con esta matriz se analizó el ¿Cómo se dijo? y ¿Qué se dijo? de cada una de las publicaciones realizadas en la página web de Diario El Comercio, lo que nos permitió entender la manera en la que se escribe la información con temas ecológicos y que características de la noticiabilidad tienen en común, en este proceso también se pudo contabilizar las fuentes de cada una de estas.

\section{Matrices de análisis de entrevistas}

Se realizó tres entrevistas a profesionales en la rama del periodismo ambiental, el periodismo digital, la docencia en periodismo especializado y educación ambiental. Las entrevistas realizadas a Arturo Larena, director de la Agencia EFE y a María Teresa Mercado docente de la Universidad CEU Cardenal Herrera, profesionales españoles se realizaron vía correo electrónico, medio por el cual se procedió a enviar los cuestionarios con 13 preguntas para cada uno respectivamente. Por su parte con Jorge Cruz experto en 
investigación de la cultura digital y medios digitales, la entrevista se realizó por medio de la plataforma zoom.

Para este proceso se utilizaron dos matrices que se muestran a continuación.

\section{a) Matriz de respuestas de entrevistados}

En esta matriz se colocó como primera parte los datos básicos de los entrevistados como son el nombre y la profesión, se detalló también los datos de la entrevista como la hora y el medio por la que esta se realizó, para finalizar se ubicó cada pregunta con su respectiva respuesta. Esta matriz se utilizó con el objetivo de tener un registro ordenado de cada entrevistado para luego clasificar la información que sería colocada en la matriz de coincidencias.

\section{b) Matriz de coincidencias de entrevistas}

En esta matriz se colocó tres categorías: tratamiento informativo, periodismo digital y periodismo ecológico y a cada categoría se le asigno tres subcategorías que se encontraban dentro de su mismo enfoque.

El objetivo de la utilización de esta matriz fue clasificar la opinión obtenida de los especialistas en las entrevistas realizadas.

\section{Enfoque}

Gráfico 1: Géneros Periodísticos.



Fuente: Tomado de la tesis de Ruiz, D.

En cuanto al uso de géneros periodísticos, se tomó en cuenta: la nota informativa, la crónica, la editorial, el comentario, la entrevista, el reportaje y la opinión.

Durante el análisis cuantitativo realizado durante los 6 meses de estudio, se encontraron 42 publicaciones, el género más utilizado fue el de la nota informativa, con un total de 37 publicaciones, se contabilizaron también 2 entrevistas y un reportaje. Como resultado 
final obtuvimos que mayo fue el mes con más noticias publicadas, registrando 19 notas informativas, una entrevista y un reportaje.

\section{Gráfico 2: Valoraciones.}

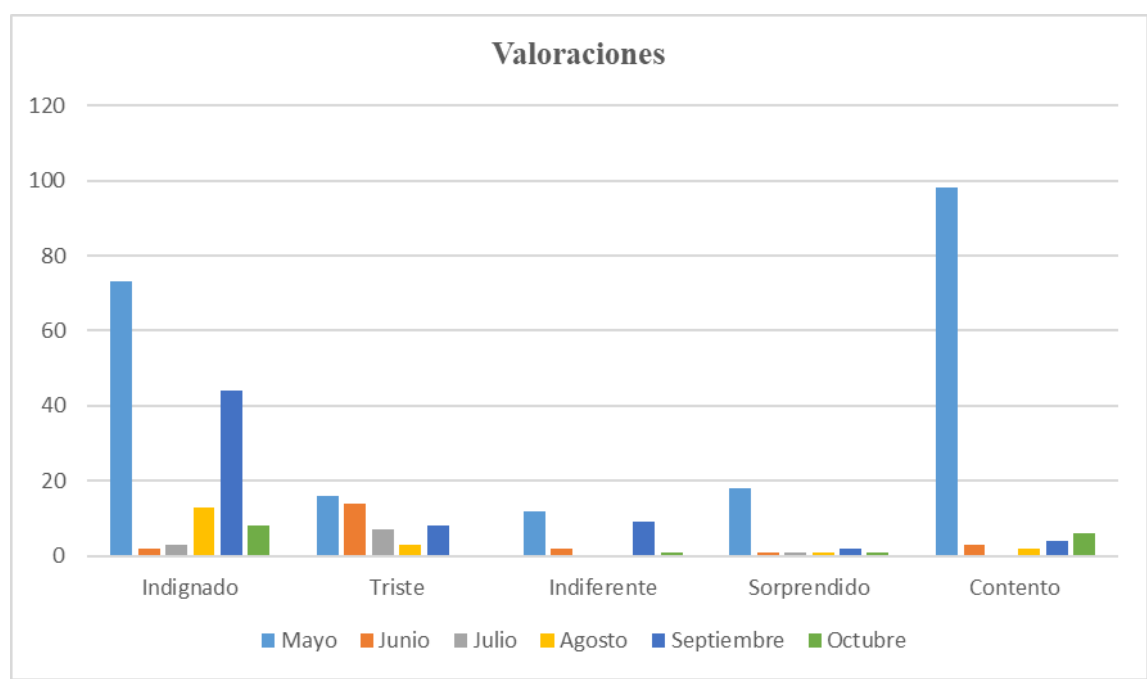

Fuente: Tomado de la tesis de Ruiz, D.

La página web de Diario El Comercio cuenta con un espacio en el que su público puede marcar una respuesta categorizada en sentimientos como: indignado, triste, indiferente, sorprendido y contento, permitiendo que desde su perspectiva de una valoración a la información publicada.

Durante el análisis encontramos que la reacción más utilizada por los usuarios fue la de indignado, la misma que fue usada en 143 ocasiones durante los seis meses de estudio, registrando en mayo y septiembre la cantidad de 73 y 44 interacciones respectivamente.

La reacción que le sigue en cantidad es la de contento siendo usada 113 veces, presentando en mayo una cantidad de 98 interacciones.

Gráfico 3: Elementos de ayuda gráfica y audiovisual.



Fuente: Tomado de la tesis de Ruiz, D. 
Para contabilizar los elementos paratextuales se los ha dividido en seis categorías: fotografías, capturas de pantalla, infografías, audios, videos e hipervínculos.

Como resultado tuvimos que el elemento más utilizado fueron los hipervínculos, contabilizando una cantidad de 67 en los seis meses estudiados, encontrando hasta 5 hipervínculos en una noticia. La fotografía es el segundo elemento más utilizado con una cantidad de 49 fotos durante los seis meses, contabilizando hasta 4 en una noticia.

En ambos casos los meses en los que más se contabilizo estos elementos fueron septiembre y mayo, con 23 hipervínculos y 26 fotografías respectivamente.

\section{Gráfico 4: Visualizaciones.}

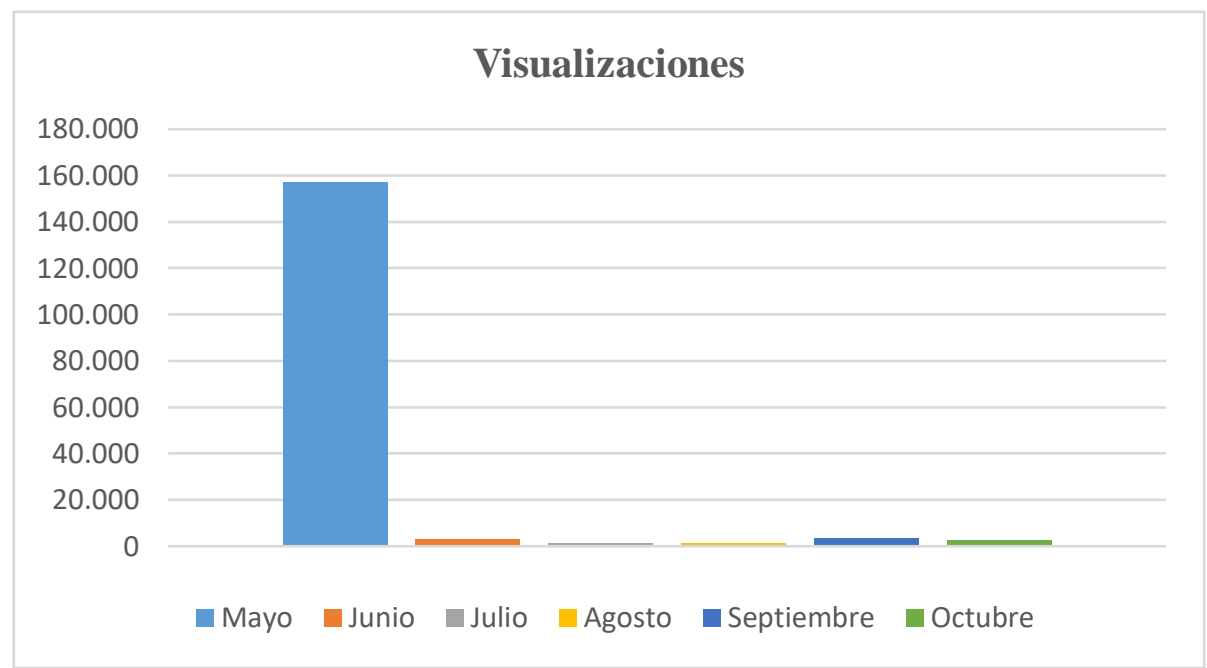

Fuente: Tomado de la tesis de Ruiz, D.

La página web de Diario El Comercio cuenta con un contador de visitas, en este caso durante los seis meses estudiados, mayo obtuvo una cantidad de 157.221 visualizaciones mientras que agosto fue el mes con menos visitas registrando una cantidad de 1.542 visualizaciones.

\section{Gráfico 5: Utilidad de la noticia.}

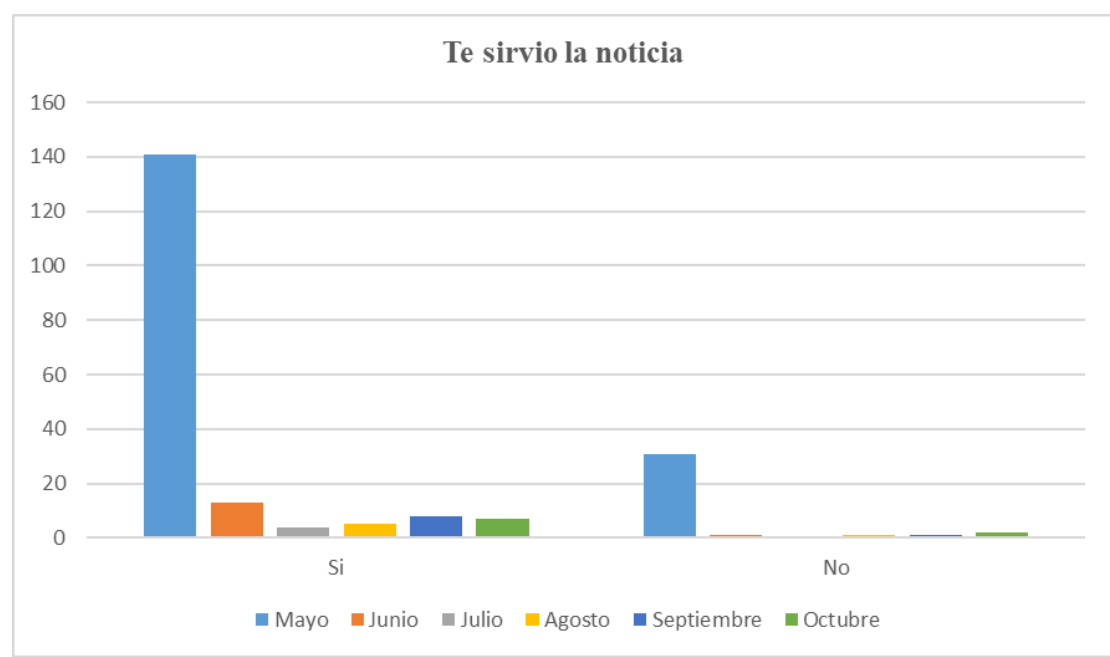

Fuente: Tomado de la tesis de Ruiz, D. 
La página web de Diario El Comercio, formula una pregunta en la que los usuarios pueden reaccionar indicando si la noticia que leyeron les sirvió, respondiendo sí o no a la misma.

En este caso encontramos que el sí tuvo una cantidad de 178 interacciones durante los seis meses analizados, registrando en mayo una cantidad 141 interacciones positivas y 31 negativas.

Gráfico 6: Fuentes.



Fuente: Tomado de la tesis de Ruiz, D.

Por medio de la matriz de cronología, se contabilizo las fuentes de cada una de las 42 noticias publicadas en la página web de Diario El Comercio, durante los meses de mayo a octubre de 2019, se encontró 13 fuentes que fueron: Agencia APF, Redacción Comercio, Agencia EFE, Gabriela Flores, Redacción Guayaquil, Isabel Alarcón, Actualidad Quito, Redacción Tendencias (F-Contenido Intercultural), Mónica Orozco Editora (I), Mayra Pacheco, Redacción Negocios, Redacción Tendencias y Diego Ortiz (Coordinador). En este caso se atribuyó 19 noticias a la Agencia EFE, 7 noticias a la Agencia AFP, mientras que las otras fuentes tuvieron de entre 5 a 1 publicación. 


\section{Conclusiones.}

- En concordancia con el objetivo específico que se refiere al tratamiento informativo sobre periodismo ecológico, se realizó un análisis de un periodo de seis meses a la página web de Diario El Comercio, en el que encontramos que se realizaron 42 publicaciones, de las cuales 37 fueron notas informativas, 2 entrevistas, 1 reportaje y 2 videos, que cumplen con los elementos de lo que se considera noticiable.

- El uso de géneros periodísticos y elementos de ayuda gráfica o audiovisual les han permitido aprovechar los beneficios que una plataforma web le otorga a los medios de comunicación nacidos en la tradicionalidad de la radio, televisión o prensa escrita, sin embargo, este medio ha constituido un vínculo de comunicación efectiva con su público, generando espacios de retroalimentación informativa con ellos.

- Durante el estudio se pudo observar que las interacciones y visualizaciones registradas en esta página web, dependían directamente del número de publicaciones que el medio realizaba, la mayoría de noticias analizadas tienen un enfoque global y no local lo que podría provocar que el público no se encuentre totalmente identificado con esta información, al sentir que lo que se informa no le afecta por completo.

\section{Referencias bibliográficas.}

Abela, J. A. (2002). Las técnicas de análisis de contenido: una revisión actualizada.

Abellán Hernández, M. y de Miguel Zamora, M. (2016): Narrativa transmedia: resignificando el consumo mediático. Presentación, Icono 14, volumen (14), pp. 1-7. Doi: 10.7195/ri14.v13i1.947

Vizuete, J. (2000). El Diario Digital. Barcelona: Bosch

Bacchetta, V. Ponencia presentada en el Primer Foro Interamericano de Periodismo Ambiental, realizado en Porto Alegre, Brasil, en el marco del XXVII Congreso de la Asociación Interamericana de Ingeniería Sanitaria y Ambiental, diciembre de 2000. MORIN, EDGAR Y KERN, ANNE BRIGITTE. Tierra-Patria, Nueva Visión, Buenos Aires, 1993. GRINBERG, MIGUEL. Edgar Morin y el pensamiento complejo, Campo de Ideas, Madrid, 2002.

Bardin, L. (1986). Análisis de contenido. Akal Universitaria. Madrid (España).

Barranquero, A. (2019). El Periodismo Social como área de especialización, perspectiva de reforma y cultura profesional. Una revisión de conceptos y debates. Estudios sobre el Mensaje Periodístico, 25(2), 667. Recuperado el 20 de enero de 2020 de https://doi.org/10.5209/esmp.64794 
Berelson, B. (1967): «Content Analysis», en Lindzey: Handbook of social psychology. Tomo I. New York, Lindzey.

Colombini, M. (2008). Anclaje social de la comunicación ambiental. Tram(p)as de la comunicación y la cultura (64), 57-60.

Coronel-Salas, G., Yaguache, J., Mier, C., Barrazueta, P., González, V., Ortiz, C., ... \& Samaniego, S. (2013). Anuario de las Empresas de Comunicación de Ecuador. UTPL.

Del Molino, A: "Narrativas transmedia", en http://es.scribd.com/doc/93396076/Narrativa-Transmedia (Última consulta: 30 de agosto de 2012).

Díaz Noci, J. (2008). Definición teórica de las características del ciberperiodismo: elementos de la comunicación digital.

Echeverría, J. (2009). Tratamiento informativo de los principios básicos. Recuperado de: file:///C:/Users/Usuario/Downloads/DialnetTratamientoInformativoDeLosPrinci piosBasicosOrgani-3719787\%20(9).pdf

Enzensberger, H. (1974): Elementos para una teoría de los medios de comunicación. Barcelona, Anagrama.

Escandón Loor, K. G. (2019). Estilo periodístico del diario digital la posta, caso ministerio de la muerte (Bachelor's thesis, BABAHOYO: UTB, 2019).

Fernández, V. L. (2000). Periodista digital: de MacLuhan a Negroponte. Revista Latina de Comunicación Social, 3(34), 0.

García-Cervigón, A. H. (2003). LA LENGUA EN EL PERIODISMO DIGITAL The language in the e-journalism. Estudios sobre el Mensaje Periodístico, 9, 177-187.

Grinberg, M. (2008). El periodismo ambiental. Tram [p] as de la Comunicación y la Cultura.

González Casanova, L. M. (2018). Análisis comparativo del tratamiento informativo sobre el caso de los "Mamanivideos" en los diarios El comercio y Ojo, marzoabril 2018.

González-Teruel, A. (2015). Estrategias metodológicas para la investigación del usuario en los medios sociales: análisis de contenido, teoría fundamentada y análisis del discurso. El profesional de la información, 24(3), 321-328.

Guerrero Bejarano, M. A. (2016). La investigación cualitativa.

Hernández, R., Fernández, C., \& Baptista, P. (2010). Metodología de la Investigación. México D.F.: Mcgraw-HILL / Interamericana Editores, S.A. de C.V. 
Larena, A. L. (2005). El periodismo ambiental, una apuesta de futuro. Ambienta: La revista del Ministerio de Medio Ambiente, (46), 56-59.

Lezamiz, A. (1997). Presente y futuro del periodismo ambiental en España. In II Congreso Nacional de Periodismo Ambiental. Madrid. Asociación de Periodistas de Información Ambiental.

López, N., \& Sandoval, I. (2016). Métodos y técnicas de investigación cuantitativa y cualitativa.

Maturana, J. (2011). Historia de Internet. Recuperado de: https://www.muycomputer.com/2011/03/14/actualidadespecialeshistoria-deinterne-19901999_we9erk2xxdd26wxifnul2ijbfv6ew_ikfzcytt2p0d440u5dug2t41nrhe_vwp34 /

Merlos, K., Ramírez, F. y Serrano, O. (2012). Tratamiento informativo que La Prensa Gráfica y El Diario de Hoy hacen de la violencia contra la mujer en el período de enero a febrero de 2012 (Tesis de Licenciatura, Universidad de El Salvador). Recuperado de: http://ri.ues.edu.sv/id/eprint/2636/1/Tratamiento\%20Informativo\%20que\%20la $\% 20$ Prensa $\% 20 \mathrm{Gr} \% \mathrm{C} 3 \%$ A0fica $\% 20 \mathrm{y} \% 20 \mathrm{El} \% 20 \mathrm{Diario} \% 20 \mathrm{de} \% 20 \mathrm{Hoy} \% 20$ hace n\%20de\%201a\%20Violencia\%20Contra\%20la\%20.pdf

Piñuel, J. L. (2002). Epistemología, metodología y técnicas del análisis de contenido. Estudios de Sociolingüística, 3(1), 1-42.

Prádanos, E. (2013). La narrativa transmedia multiplica exponencialmente las posibles vías de monetización. Recuperado el, 2.

Pérez-luque, M.: "El reto de crear noticias online. Análisis de la comunicación online actual y perspectivas del futuro". Cuadernos de Documentación Multimedia, Universidad Complutense de Madrid, Madrid, 1999, http://www.ucm.es/info/multidoc/revista/cuad6-7/noticias.htm

Pulido Polo, M. (2015). Ceremonial y protocolo: métodos y técnicas de investigación científica.

Raigada, J. L. P. (2002). Epistemología, metodología y técnicas del análisis de contenido. Sociolinguistic Studies, 3(1), 1-42.

Ramos, A. (coord.). (2017). Periodismo del siglo XXI. México: NOTIMEX y CONEICC. $\begin{array}{lllllll}\text { Recuperado el } & 28 & \text { de } & \text { abril de } & 2020 & \text { de }\end{array}$ http://www.notimex.gob.mx/multimedia/ebook/v2/NTXBook.pdf

Ramos, C. A. (2015). Los paradigmas de la investigación científica. Avances en psicología, 23(1), 9-17. 
Royo, J. (2004). Diseño digital, Barcelona, Paidós.

Ruiz, D. (2020). Análisis del tratamiento informativo sobre periodismo ecológico en la página web de Diario el Comercio, periodo mayo - octubre 2019” [Título profesional, Universidad Nacional de Chimborazo]. Repositorio Académico de la Universidad Nacional de Chimborazo. http://dspace.unach.edu.ec/bitstream/51000/6818/1/TESIS\%20Daniela\%20Ruiz $\% 20$ S\%c3\%a1nchez\%20-COM-SOC.pdf

Salaverría, R. (2004). Prensa/ diseñando el lenguaje para el ciberperiodismo. Revista Latinoamericana de Comunicacación CHASQUI, 39.

Sánchez, A. S. T. (2018). Los retos de la enseñanza universitaria del periodismo digital emprendedor en México. Global Media Journal, 15(29), 5-21.

Scolari, C. (2017). El translector. Lectura y narrativas transmedia en la nueva ecología de la comunicación. La lectura en España. Informe, 175-186.

Valenzuela Polanco, M. J. (2020). Periodismo ambiental en Colombia: Análisis comparativo sobre el cubrimiento de los diarios web El Tiempo y El Espectador (Doctoral dissertation, Universidad del Rosario).

Vega, M. Á. O. (2017). Análisis del periodismo en múltiples soportes, dispositivos y plataformas: narrativa transmedia, sinergias y convergencia entre formatos (Doctoral dissertation, Universidad Complutense de Madrid).

Zalcberg, A. (2001). El ciberperiodismo. Estudios sobre el mensaje periodístico, 2001(7), $167-184$

\section{LCiencia}




\section{PARA CITAR EL ARTÍCULO INDEXADO.}

Zambrano Pontón, R. G., Ruiz Sánchez, D. C., Murillo Naranjo, M. E., \& Haro Velasteguí, F. A. (2021). Tratamiento informativo sobre periodismo ecológico en la página web de Diario El Comercio. ConcienciaDigital, 4(3.1), 76-94. https://doi.org/10.33262/concienciadigital.v4i3.1.1813

\section{¿Ciencia}

El artículo que se publica es de exclusiva responsabilidad de los autores y no necesariamente reflejan el pensamiento de la Revista Conciencia Digital.

El artículo queda en propiedad de la revista y, por tanto, su publicación parcial y/o total en otro medio tiene que ser autorizado por el director de la Revista Conciencia Digital.

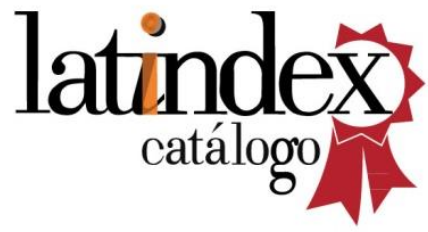

